\title{
MASS SPECTROMETER CALIBRATION OF COSMIC DUST ANALYZER
}

\author{
G. Jyoti, Satish C. Gupta, T. J. Ahrens, Dmitri Kossakovski ${ }^{1}$ and J. L. Beauchamp ${ }^{1}$
}

Lindhurst Laboratory of Experimental Geophysics, Seismological Laboratory, ${ }^{1}$ Arthur Amos Noyes Laboratory of Chemical Physics, California Institute of Technology, Pasadena CA 91125.

\begin{abstract}
The time of flight mass spectrometer of the Cosmic Dust Analyzer (CDA) instrument aboard the Cassini spacecraft, is expected to be placed in orbit about Saturn to sample the ring material and satellite impact ejecta. Upon impact of an incident dust particle against the target plate at velocities of $5-100 \mathrm{~km} / \mathrm{s}$, some $10^{-8}$ to $10^{-5}$ times the particle mass of positive valence, single-charged ions is induced. These are analyzed via a time-of-flight mass spectrometer. Initial experiments employing a pulsed $\mathrm{N}_{2}$ laser ( $>300 \mu \mathrm{J} /$ pulse, $4 \mathrm{~ns}, 337 \mathrm{~nm}$ ) acting on a suite of samples are described. The laser beam is focussed to deliver the light pulses onto a laser power density $\left(10^{11} \mathrm{~W} / \mathrm{cm}^{2}\right)$ to simulate the impact of particles. Laser ionization produced a charge of $4.6 \mathrm{pC}$ per pulse for aluminum alloy. Estimating that each $\mathrm{Al}^{+1}$ ion require energy of $5.98 \mathrm{cV}$ ionization energy/ion implies that $10^{-5} \%$ of the laser energy produced ions and the present system has a 5\% efficiency of collecting the laser-irradiation induced ions. Employing a multi-channel plate detector in this mass spectrometer yields for $\mathrm{Al}-\mathrm{Mg}-\mathrm{Cu}$ alloy and kamacite (Fe-Ni mineral) targets well defined peaks at $24\left(\mathrm{Mg}^{+1}\right), 27\left(\mathrm{Al}^{+1}\right)$ and $64\left(\mathrm{Cu}^{+1}\right)$, and $56\left(\mathrm{Fe}^{+1}\right)$, $58\left(\mathrm{Ni}^{+1}\right)$ and $60\left(\mathrm{Ni}^{+1}\right)$ dalton, respectively.
\end{abstract}

\section{INTRODUCTION}

One of the objectives of the Saturn orbiter, Cassini spacecraft is to characterize the dust/meteoroid environment of the Saturnian ring and satellite system. For this purpose the orbiter is equipped with a Cosmic Dust Analyzer (CDA) instrument ${ }^{1}$. The CDA measures the charge, the impact speeds, the mass and composition of these dust particles. The micrometeoroid mass measurement range is $10^{-15}$ to $10^{-9} \mathrm{~g}$ and the speed measurement range is 1 to $100 \mathrm{~km} / \mathrm{s}$. An integrated time-of-flight impact ionization (Chemical Analyzer) mass spectrometer provides constraints on the particle's chemical composition. Particles impacting onto the Rh target plate (fig 1a), of this instrument and some mass of the Rh target itself, get vaporized and partially ionized. The positive ions (mostly singly charged) so produced get accelerated to $10^{3} \mathrm{eV}$ energy. Providing no equidalton interference exists, the time of arrival of ions provide mass spectra for each dust particle in the above mass range. The dust analyzer has two types of ion detection systems, onc is a charge sensitive amplifier (CSA) and the other is an electron multiplier ${ }^{2}$.

Impact ionization experiments that determine the species type have been carried out ${ }^{3}$, previously, with test spheres with diameters of $0.2 \mu \mathrm{m}$ to 20 $\mu \mathrm{m}$. Such particles with mass of $10^{-15}$ to $10^{-9} \mathrm{~g}$ are electrostatically accelerated to velocities of 1 to 70 $\mathrm{km} / \mathrm{s}$. The type of particles that can be accelerated by this method are conducting, or coated with a conducting (metal or carbon) film. These experiments, however, were limited to commercial availability of conducting microspheres. 


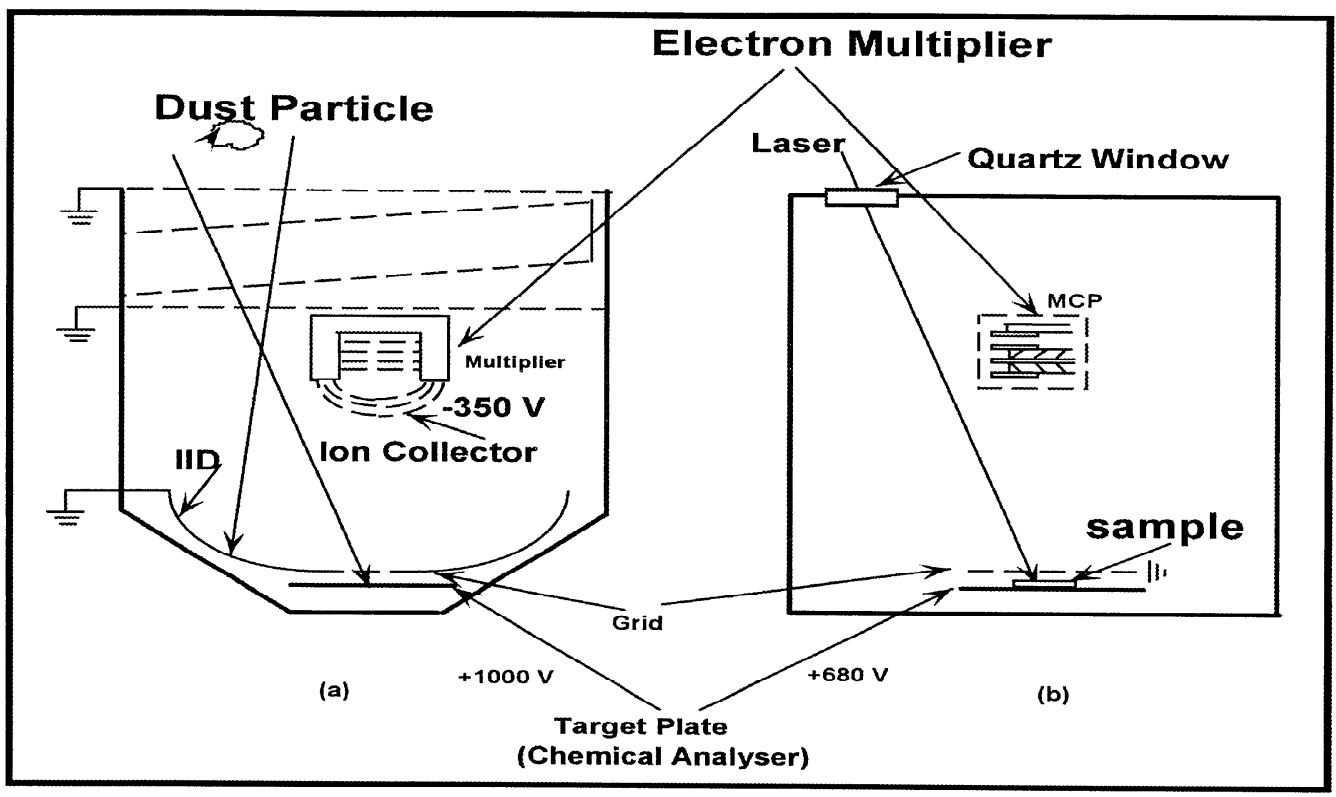

FIGURE 1. a) sketch of the CDA instrument aboard Cassini mission, simulated by the b) laser ionization TOF mass spectrometer at our laboratory.

For larger particles having diameter of the order of $100 \mu \mathrm{m}$, we expect to employ a light gas-gun for launching a wide range of projectiles of cosmochemical importance to velocities up to $\sim 6$ $\mathrm{km} / \mathrm{sec}$. These velocities are comparable to the circular orbit speeds around Saturn, the larger Saturnian satellites and ring-plane particles (5-10 $\mathrm{km} / \mathrm{s}$ ). Because of the difficulty in launching a single microspheric projectile with a light gas-gun, and, also to provide the pulsed ion source for setting-up the calibration electronics, the initial calibration has been initiated using a laser pulse. Since the particle-target interaction times ( 10ns) and energies of dust particles are comparable to the duration and energies of available pulsed laser $^{4}$, laboratory laser ionization experiments are useful to optimize the instrumentation for impact experiments. Figure 1 shows the correspondence between our laser ionization time of flight mass spectrometer (on mock-up instrument) and the CDA instrument now aboard the Cassini spacecraft.

We employ a $4 \mathrm{~ns}, 337 \mathrm{~nm}, 300 \mu \mathrm{J}$, pulsed nitrogen laser with a energy density of $\sim 9.0 \times 10^{2}$ $\mathrm{J} / \mathrm{cm}^{2}$ and a focal spot diameter of $\sim 6.5 \mu \mathrm{m}$. The incident laser energy density $\left(\sim 10^{11} \mathrm{~W} / \mathrm{cm}^{2}\right)$ simulates the impact of particles with various combinations of density and velocity, e.g. $\sim 8 \mathrm{~g} / \mathrm{cm}^{3}$ (Fe) and $1 \mathrm{~g} / \mathrm{cm}^{3}$ projectile at 23 and $65 \mathrm{~km} / \mathrm{s}$, respectively. Normally, particles having densities in $\sim 0.01$ to $5 \mathrm{~g} / \mathrm{cm}^{3}$ range are expected to be encountered in space. That could range in composition from those similar to planetary ice, carbonaceous chondrites and possibly correspond to Brownlee $^{6}$ particles to differentiated silicate metal and asteroid fragments.

\section{EXPERIMENTAL METHOD}

In the mock-up instrument, the laser beam enters the chamber through a quartz window and is focused onto the target with a fused silica $10 \mathrm{~cm}$ focal length lens. The laser pulse is triggered externally. Just before the onset of the laser pulse, the oscilloscope is triggered by optosynchronous signal provided by the laser electronics. The timeof-flight mass spectrometer chamber pressure was maintained below $1.0 \times 10^{-6}$ mbar with a $1500 \mathrm{l} / \mathrm{s}$ diffusion pump. Upon laser pulse incidence, the ions are formed in a small volume source region between the target plate and the grid. The target plate is made of commercial aluminum alloy on which samples of a few mm diameter and 0.10 to 
$0.15 \mathrm{~mm}$ thickness are mounted. Similar to that in CDA, we have employed two kinds of ion detection systems, i.e. the charge sensitive amplifier (CSA) with copper collector plate and the multichannel plate (MCP) detector. However, these two detectors have not been used simultaneously but in separate experiments. The time resolution (a few ns) of the MCP is comparable to MM1 multiplier used in CDA. The experiments were conducted in two different configurations of the mass spectrometer. In the first configuration, the plate was applied a voltage of $680 \mathrm{~V}$ (grid grounded), the distance between the plate and the grid was $6 \mathrm{~mm}$, whereas the separation between the target and the detector was $280 \mathrm{~mm}$. In the second configuration, the voltage and distances values were $1000 \mathrm{~V}, 3 \mathrm{~mm}$ $230 \mathrm{~mm}$, respectively. In the latter configuration, our TOF mass spectrometer closely simulates the Chemical Analyzer part of the CDA instrument.

\section{RESULTS}

In the first configuration, experiments were carried out on commercial aluminum sample employing both CSA and MCP. The target plate itself was treated as a sample. Using CSA, at low laser power densities, a two-step pulse corresponding to ${ }^{23} \mathrm{Na}^{+1}$ and ${ }^{39} \mathrm{~K}^{+1}$ with approximately $350 \mathrm{~ns}$ rise time each, was observed. Presence of contaminant alkali salts from fingerprints on the sample surface is well known in mass spectrometry. The known mass of the $\mathrm{Na}^{+}$and $\mathrm{K}^{+}$ions is advantageously used for calibrating the instrument. With higher laser power density, a highamplitude, long duration ( $800 \mathrm{~ns}$ ) pulse was observed. This pulse, in fact could be associated with the overlap of two pulses, corresponding to the arrival of ${ }^{23} \mathrm{Na}^{+1}$ and ${ }^{27} \mathrm{Al}^{+1}$ (fig. 2a). No further steps were observed. This shows that the elements separated by four mass numbers could not be resolved using CSA detector. The clectron flux from the target plate, estimated to be around $4.7 \mathrm{pC}$, is controlled by the amplitude of the charge generated by the production of positive ions and the condition that charge neutrality is maintained. The positive ion charge collected at the collector plate was estimated to be $0.23 \mathrm{pC}$. This corresponds to an ion detection efficiency of 4-5\% over a $\sim 0.09 \mathrm{sr}$ collection solid angle. Estimating that each $\mathrm{Al}^{+1}$ ion
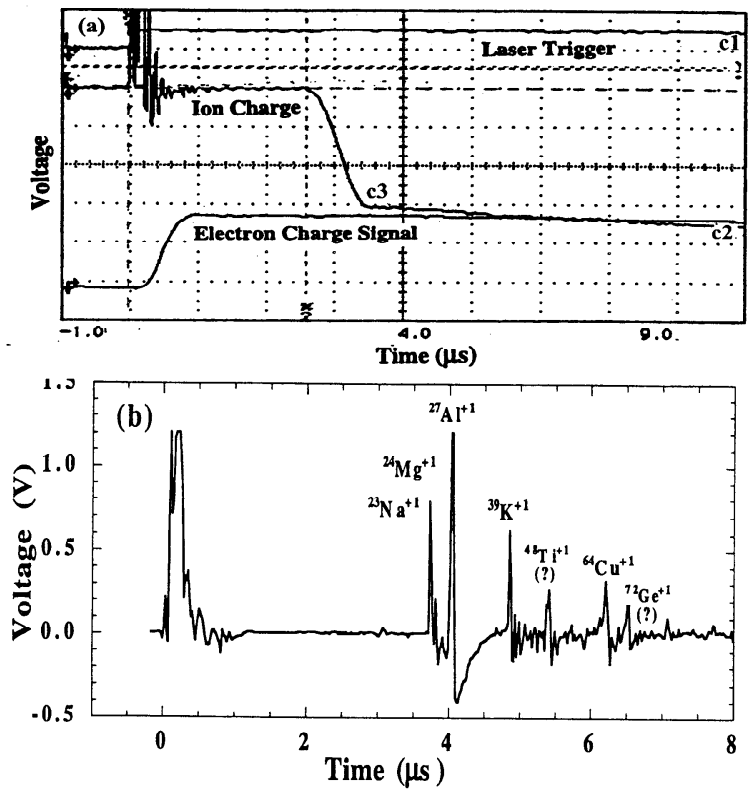

FIGURE 2. Single laser pulse time of flight spectra recorded from $\mathrm{Al}$ alloy sample a) using charge sensitive amplifier. (c1, c2 and $c 3$ are the output due to laser trigger (5V/div), integrated electron charge at the target end $(200 \mathrm{mV} / \mathrm{div})$ and ion signal at the collector plate ( $75 \mathrm{mV} / \mathrm{div})$, respectivcly) b) using MCP

requires energy of $5.98 \mathrm{eV} / \mathrm{ion}$ implies that $10^{-5} \%$ of the laser energy has produced ions. Fig. 3b displays the $\mathrm{Al}$ spectra recorded with $\mathrm{MCP}$ detector. It shows a well defined singly charged aluminum peak along with peaks corresponding to ${ }^{23} \mathrm{Na}^{+1}$ and ${ }^{39} \mathrm{~K}^{+1}$. Peaks corresponding to $\mathrm{Cu}^{+1}$ and $\mathrm{Mg}^{+1}$ are low level concentration aluminum alloying elements.

In the second configuration, the sample material used was kamacite ${ }^{6}(94.5 \% \mathrm{Fe}$ and $5.5 \% \mathrm{Ni})$ which is the principal mineral in $\mathrm{Fe}-\mathrm{Ni}$ meteorites. Meteorite Gibcon was the source of our sample. Fig. 3 shows the spectra for kamacitc. Here, aside from the two peaks observed earlier from contaminants $\left({ }^{23} \mathrm{Na}^{+1}\right.$ and $\left.{ }^{39} \mathrm{~K}^{+1}\right)$ a peak at $41 \mathrm{amu}$, which can be indexed as ${ }^{41} \mathrm{~K}^{+1}$, is also observed. The 39 and $41 \mathrm{amu}$ isotopes of potassium having a natural abundance of $93.2581 \%$ and $6.7302 \%$, respectively, that gives the abundance ratio of 13.85, show a peak height ratio of 15.50 and 15.88 , respectively in the two spectra. Now, as expected from this mineral, both $\mathrm{Fe}$ and $\mathrm{Ni}$ peaks are seen. It is important to note here, that though $\mathrm{Fe}$ and $\mathrm{Ni}$ 


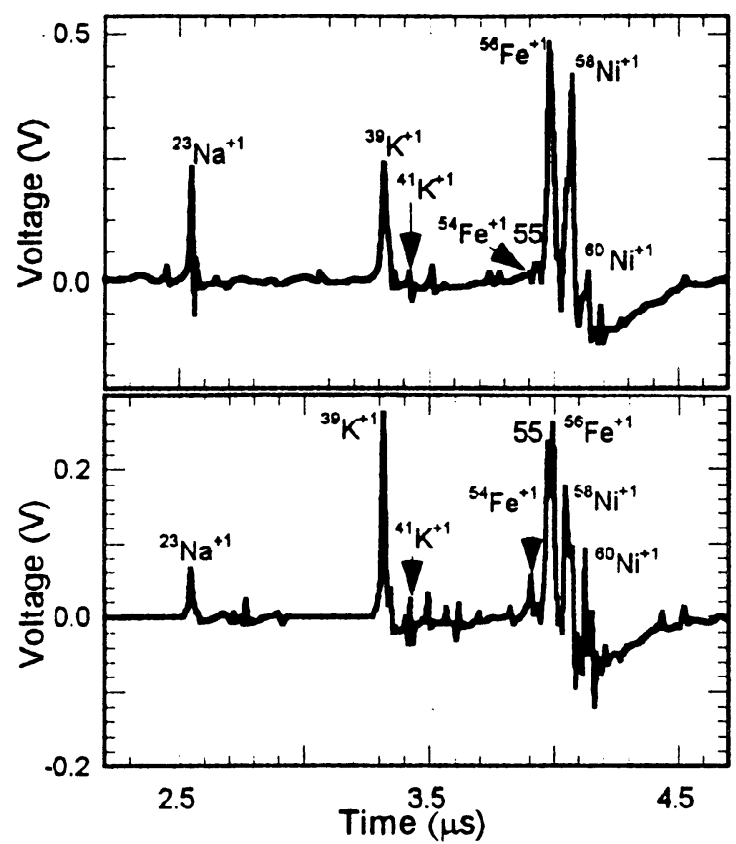

FIGURE 3. Two single laser pulse time of flight spectra from kamacite.

abundance ratio in kamacite is 17.18 , the peak height ratio in the two spectra are 1.15 and 1.48 only (Fig.3). Even though we consider the fact that the ionization potential of $\mathrm{Ni}(7.64 \mathrm{eV})$ is lower than that of $\mathrm{Fe}(7.90 \mathrm{eV})$, it may not explain the large disparity between the two ratios. Also, $\mathrm{Ni}$ has a natural concentration of $68.077 \%,{ }^{58} \mathrm{Ni}$ and $26.22 \%,{ }^{60} \mathrm{Ni}$, so that the ratio of their abundances is 2.59. However, the ratios of the peak heights of the ions of these isotopes from the two observed spectra are as high as 35.34 and as low as 1.98 . Similarly, for iron, the natural abundance of the two isotopes ${ }^{56} \mathrm{Fe}$ and ${ }^{54} \mathrm{Fe}$ being $91.72 \%$ and $5.8 \%$, the abundance ratio is 15.81 but the ratio of the peak heights for these isotopes from the two observed spectra are 24.40 and 5.30, respectively. Both the spectra show a peak at $55 \mathrm{amu}$, which could belong to ${ }^{55} \mathrm{Mn}^{+1}$.

\section{SUMMARY}

Using a $300 \mu \mathrm{J}, 4 \mathrm{~ns}, 337 \mathrm{~nm}$ laser, we have setup a mock-up instrument of CDA employing both the charge sensitive amplifier and multichannel plate detectors. In this instrument, with charge sensitive amplifier as a detector, the elements with masses differing by 4 amu could not be distinguished but with the multi-channel plate as detector not only these elements were well resolved but ion signals could also be observed from several elements that are present at low levels of concentration in the sample. This mock-up instrument was used to generate mass spectra for the mineral kamacite. In kamacite, we observe that peak height for an element and/or isotopes of an element is not proportional to the abundance of that element in the material or that isotope in the element, respectively. Peak height ratios of different elements and/or of isotopes of same elements are different from shot to shot. With this mock-up instrument when the mass number of the element is in 55-56 amu range, spectral peaks for mass numbers differing by $1 \mathrm{amu}$ are well resolved.

The data generated by the CDA instrument is expected to determine the chemical composition of any unknown sample from the recorded mass spectra. To carry out this task requires the understanding of the physics of impact vaporization and ionization in materials. For this, one needs to generate a data base from a number of spectra from as many minerals of known chemical composition and abundances, using both the laser ionization process and impact ionization process (using gasgun) in order to arrive at a physics based model that could explain and interpret the spectra.

\section{ACKNOWLEDGEMENTS}

Research supported by NASA. Contribution number 8671 of Division of Geological and Planctary Sciences, (Caltech)

\section{REFERENCES}

1. Grün E., Zook H.A., Fechtig H and Giese R.H., Icarus 62, 244 (1985).

2. Linda J Spilker, Passages to a Ringed World, NASA publication, NASA SP-533 (1997).

3. Grün E., Fechtig H., Hanner M.S., Kissel J., Lindblad B., Linkert D., Maas D., Morfill G. E. and Zook H.A., Space Science Reviews 60, 317 (1992).

4. Kissel J. and Krüeger F.R., Appl. Phys. A 42, 69 (1987).

5. G. Jyoti, Satish C. Gupta, T. J. Ahrens, Dmitri Kossakvski and J. L. Beauchamp, Proceedings of the 1998, Hyper Velocity Impact Symposium, Alabama, USA.

6. Mason B, Meteorites (Wiley, New York \& London) 1962. 